\title{
Spatial and temporal variability in dispersal and population genetic structure of a rockpool alga
}

\author{
M. A. Coleman*, S. H. Brawley \\ School of Marine Sciences, 321 Hitchner Hall, University of Maine, Orono, Maine 04469, USA
}

\begin{abstract}
We describe the population dynamics of a rockpool alga and identify a novel mechanism that allows dispersal where it would otherwise be limited. Fucus distichus L. is a monoecious seaweed restricted to high intertidal rockpools. It reproduces from December to mid-May in Maine, USA. Densities vary greatly among pools (0.05 to 80 individuals $\left.\mathrm{m}^{2}\right)$ and extinctions or declines in abundances occur periodically. Gamete release occurs at low, neap tides when pools are isolated from bulk seawater. We proposed that genetic structure among rockpools would be high, and genetic diversity within pools would be low. We used 4 microsatellites to characterize genetic structure and diversity in pools at Schoodic (3 sites) and Chamberlain (2 sites) in Maine. Genetic differentiation existed between Schoodic and Chamberlain $\left(F_{\mathrm{ST}}=0.146\right)$, among sites $\left(F_{\mathrm{ST}}=0.095\right)$ and among pools within sites $\left(F_{\mathrm{ST}}=0.237\right)$. An excess of homozygotes characterized most pools. Many adults in each pool were classified as first generation migrants, indicating high levels of past gene flow. Current gene flow (recruitment) occurred among adjacent pools. Laboratory studies on zygote attachment, and field data on gamete release were used to model dispersal potential. Attachment of zygotes at cold seawater temperatures $\left(5^{\circ} \mathrm{C}\right)$ was slow enough to permit dispersal for at least 5 high tides following gamete release. The unusual reproductive seasonality of $F$. distichus may be an adaptation that mitigates ecological and evolutionary bottlenecks associated with its patchy habitat.
\end{abstract}

KEY WORDS: Dispersal - Genetic structure - Fucus distichus - Population - Reproduction · Rockpools · Phenology

\section{INTRODUCTION}

Analysis of patterns of dispersal, colonization and genetic structure is one of the primary goals of population ecology. Understanding what causes and maintains these patterns is particularly important in habitats that are patchy or fragmented in space where dispersal of organisms may be restricted on several scales. Spatial and temporal dynamics among patches are often described using metapopulation (Levins 1969, Hanski \& Gilpin 1997), source-sink (Pulliam 1988), stepping-stone (Maruyama \& Kimura 1980) and island-mainland (Wright 1943, MacArthur \& Wilson 1967) models. Such models depend largely on the dispersal capabilities of the organism relative to the spatial arrangement of patches of habitat.

Dispersal among patches of habitat can be restricted when distances among patches are larger than the scale on which organisms have the ability to disperse
(Wright 1943, Brown 1971), when physical barriers are present (Mader 1984, Neraas \& Spruell 2001, Won et al. 2003) or when there is variability in the presence or effectiveness of vectors of dispersal (Powell \& Powell 1987, Barnay et al. 2003, Marshall et al. 2004). Low levels of dispersal result in low levels of gene flow among populations, which causes them to become genetically distinct through effects including mutation, selection and genetic drift. Without gene flow, inbreeding can cause local populations to become extinct (Soule 1980, Gabriel et al. 1993, Lande 1993, Newman \& Pilson 1997, Frankham 1998, Saccheri et al. 1998, Lynch et al. 1999). Recolonization of empty habitat from specific (mainland, island or source) or adjacent populations is an important structuring force for many populations. Recolonization can create genetic differentiation via founder effects, where individuals that recolonize patches are genetically distinct, and these differences are maintained through time (Mayr 1954, Wade \& 
McCauley 1988, Provine 1989, McCauley 1991, Hansen \& Mensberg 1996).

Here, we test hypotheses about patterns of dispersal and genetic structure and diversity in a rockpool alga. Fucus distichus L. (= F. distichus L. subsp. distichus L. emend. H. T. Powell), an intertidal fucoid alga with a patchy distribution, occurs predominantly in high shore rockpools and seldom on surrounding emergent substrata (Chapman \& Johnson 1990). Massive declines in abundance, as well as extinction of $F$. distichus from rockpools that previously supported dense populations, have been observed at some sites in Maine (S. H. Brawley pers. obs.). F. distichus is sympatric on the New England shore with several other fucoids (F. spiralis L., F. vesiculosus L., F. evanescens C. Ag., Ascophyllum nodosum L. Le Jol.) but is the only one that reproduces in winter at low seawater temperatures $\left(-4\right.$ to $8^{\circ} \mathrm{C}$ in rockpools). Gametes of $F$. distichus are released during daytime low tides at neap portions of the tidal cycle when water exchange among pools is minimal (Pearson \& Brawley 1996). Indeed, on some neap tides these pools are isolated from bulk seawater for several days. Fertilization success is high (between 78 and 100\%) and occurs before pools are washed by the next incoming tide (Pearson \& Brawley 1996). There is some evidence to suggest that the cold seawater temperatures experienced by this species in winter and early spring may delay the attachment of zygotes (Pearson \& Brawley 1996). Thus, despite rapid fertilization and frequent isolation of pools from bulk seawater, dispersal among rockpools may be facilitated via this mechanism.

First, we tested hypotheses regarding dispersal and colonization/migration among rockpools containing Fucus distichus to determine the level of connectivity among patches of habitat. We hypothesized that genetic diversity within rockpools would be low, dispersal among pools would be infrequent, and zygotes would tend to settle and grow in the pools from which they originated. Consequently, we predicted that population genetic structure of $F$. distichus would be high among rockpools. Second, we used demographic data to estimate levels of extinction and recolonization of $F$. distichus among patches of habitat. Given the observation that massive declines in abundance have occurred previously at some sites (S. H. Brawley pers. obs.), we predicted that declines in abundance and extinctions are common. We also used these data to follow recolonization through time and identify spatial scales of dispersal. Finally, we tested the hypothesis that temperature is a mechanism that allows $F$. distichus to disperse more widely than predicted, which may explain its persistence in such a patchy, isolated habitat.

\section{MATERIALS AND METHODS}

Fucus distichus individuals were sampled in March 2002 from Schoodic $\left(44^{\circ} 21.928^{\prime} \mathrm{N}, 68^{\circ} 04.613^{\prime} \mathrm{W}\right)$ and Chamberlain $\left(43^{\circ} 83.702^{\prime} \mathrm{N}, 69^{\circ} 50.643^{\prime} \mathrm{W}\right)$, which are separated by approximately $500 \mathrm{~km}$ of shore comprising many bays and peninsulas on the Maine (USA) coast (Fig. 1). At Schoodic, 5 rockpools containing F. distichus were selected at each of 3 randomly chosen

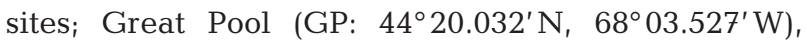
Schoodic Point (SP: 44 ${ }^{\circ} 19.977^{\prime} \mathrm{N}, 68^{\circ} 03.671^{\prime} \mathrm{W}$ ) and Blueberry Hill (BH: $44^{\circ} 20.585^{\prime} \mathrm{N}, 68^{\circ} 02.632^{\prime} \mathrm{W}$ ). $\mathrm{BH}$ is $1.5 \mathrm{~km}$ from GP, which is $0.75 \mathrm{~km}$ from SP. Within each site, distances between rockpools varied, but were a maximum of $30 \mathrm{~m}$ from each other and at least $30 \mathrm{~cm}$ apart. At each site, the rockpools sampled represented the majority of the pools containing $F$. distichus present on that stretch of shore. Similarly, 4 rockpools were sampled at each of 2 sites at Chamberlain (Chamberlain A and B separated by 50 m, see Pearson \& Brawley (1996) for a map of these sites and rockpools). At each
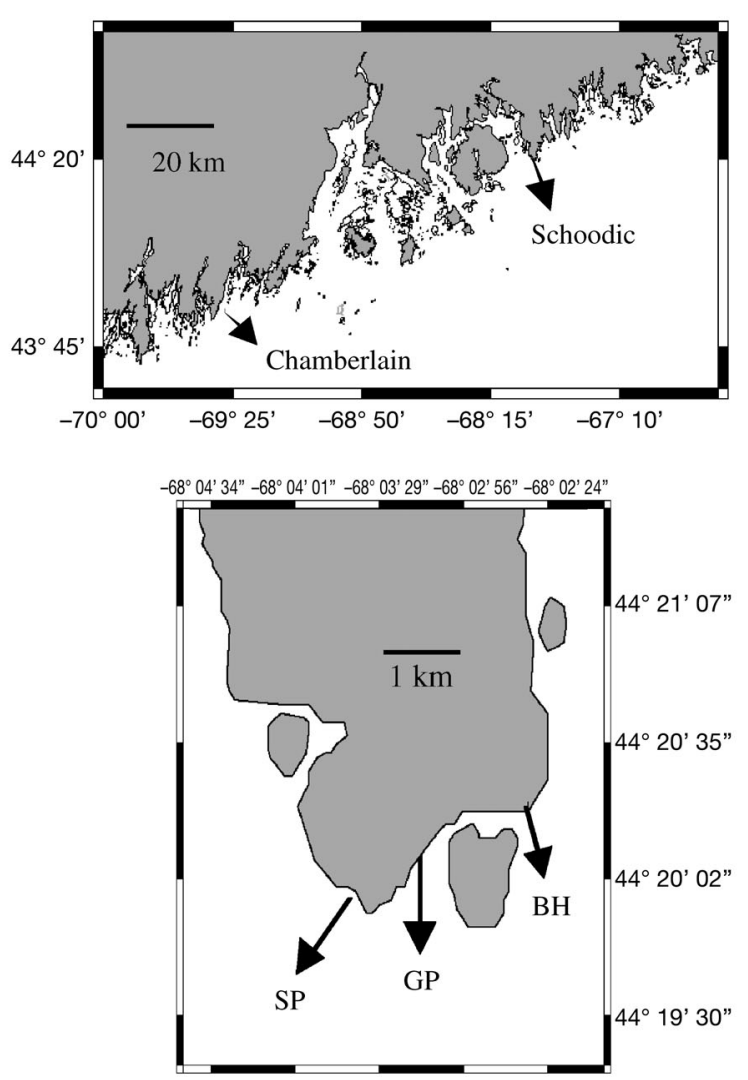

Fig. 1. Map showing position of Schoodic and Chamberlain on the coast of Maine, USA. See Pearson \& Brawley (1996) for maps of Chamberlain pools. Coastline maps were generated using Coastal Extractor (www.ngdc.noaa.gov/mgg/shore lines/shorelines.html). SP: Schoodic Point; GP: Great Pool; BH: Blueberry Hill 
Chamberlain site, rockpools were all within $8 \mathrm{~m}$ of each other. Between 5 and 40 individuals were nondestructively sampled within each pool, depending on abundances within that pool (some pools only contained 5 individuals while others had over 1000 individuals). Given the reproductive ecology of this species, we regarded sites within each location to be separated by large enough distances (tens of meters to kilometers) to represent distinct populations with little gene flow. In particular, uninhabitable areas such as boulder fields with no rockpools separated many sites. Distances among rockpools are fixed by nature and are a conspicuous ecological subdivision of habitat. Determining whether these ecologically subdivided habitats (rockpools) also represent distinct genetic populations or a single panmictic population was one of the aims of this study.

Several vegetative apical tips were removed in the field from each sampled individual and stored at $-80^{\circ} \mathrm{C}$. We used a CTAB/Sephaglas ${ }^{\mathrm{TM}}$ (Amersham Pharmacia Biotech) procedure to extract DNA (Coyer et al. 2002). Four polymorphic microsatellite loci were used to quantify genetic variation in Fucus distichus. These were L38 (GCT), L58 (GA), L20 (CTG) and L94 (GCA) (Engel et al. 2003). Samples were diluted to $0.02 \mathrm{ng}$ DNA $\mu \mathrm{l}^{-1}$ for PCR amplification. Polymerase chain reactions (PCR) were performed in $20 \mu$ volumes containing $2 \mathrm{mM} \mathrm{MgCl}, 100 \mu \mathrm{M}$ dNTPs (Invitrogen), $2505 \mathrm{nM}$ forward primer (2:3 labeled:unlabeled, Operon), $250 \mathrm{nM}$ reverse primer (Operon), $0.5 \mathrm{U}$ Taq (Promega), $1 \times$ buffer (diluted from 10× Promega buffer) and water to adjust volume to $20 \mu \mathrm{l}$ per reaction. PCRs used the thermocycler conditions specified for each locus in Engel et al. (2003) and products were separated on an ABI 377 automated sequencer. Alleles were scored using Genescan and Genotyper (Applied Biosystems).

Prior to conducting statistical analyses, we checked for genotyping errors (null alleles, stuttering, allele drop out and typographical errors) using MICROCHECKER (van Oosterhout et al. 2004). By identifying specific patterns in the data (e.g. deficiencies and excesses of particular genotypes) that are unique to each of the above effects, this program is able to distinguish such genotyping problems from 'real' departures from panmixia (van Oosterhout et al. 2004). Patterns of genetic diversity were characterized using a number of descriptive measures. The total number of alleles, number of unique alleles, observed $\left(H_{0}\right)$ and expected $\left(H_{\mathrm{e}}\right)$ heterozygosities were estimated for each spatial scale using GENETIX ver. 4.04 (Belkhir et al. 2000). $F_{\mathrm{IS}}$ is an estimate of inbreeding of individuals relative to the sub-population. $F_{\text {IS }}$ estimates range from -1 to 1 with negative estimates indicating an excess of heterozygotes and positive estimates an excess of homo- zygotes. In addition, we tested for Hardy-Weinberg equilibrium at each locus by randomizing alleles within each site, and over all sites using FSTAT 1.2 (Goudet et al. 1995). Patterns of genetic structure were visualized using nearest neighbor joining trees made in PHYLIP (Felsenstein 2002) and drawn in TREEVIEW (Page 1996) using a matrix of Reynolds genetic distances (Reynolds et al. 1983). The relative strength of groups was measured using bootstrap values generated using 1000 permutations (PHYLIP, Felsenstein 2002). Genetic structure was determined by testing Weir and Cockerham's $F_{\mathrm{ST}}$ and $F_{\mathrm{IS}}$ estimates (Weir \& Cockerham 1984) using permutation tests (1000 permutations, FSTAT 1.2, Goudet et al. 1995). $F_{\mathrm{ST}}$ estimates genetic diversity (inbreeding of sub-populations relative to the total) and ranges from 0 to $1 ; F_{\mathrm{ST}}=0$ corresponds to no genetic diversity. Pairwise $F_{\mathrm{ST}}$ estimates were also calculated between pools and between sites. The Bonferroni correction was used when examining significance levels for pairwise tests. We did not assume random mating so genotypes rather than alleles were permuted. Analysis of molecular variance (AMOVA) was done in ARLEQUIN ver. 2.00 (Schneider et al. 2000) to determine the percentage of variation explained at each spatial scale. We did not assume a stepwise mutation model. A significance level of $\mathrm{p}<$ 0.05 was used. We identified potential first generation migrants using GeneClass 2 (Piry et al. 2004) as an indirect measure of past dispersal. Assignment tests are limited by the number of potential 'source' populations sampled. That is, an individual will be assigned to 1 (the most likely) source population, even if there is a low probability of it actually coming from that population. To assess this problem, Gene Class 2 uses Monte Carlo resampling techniques to compute the probability of an individual belonging to each given source population. We predicted that most individuals would be assigned to the pool from which they were sampled. In addition, assignment tests were done on genotypes of recruits to determine the most likely pool of origin. We hypothesized that recruits would be assigned to the pool from which they were sampled. Both tests were done using the Rannala \& Mountain (1997) Bayesian method of computing genotypes because this method often performs better than distance based methods (Cornuet et al. 1999, Berry et al. 2004), particularly when the number of loci and number of replicates are small (Cornuet et al. 1999). Tests of isolation by distance were done via a Mantel test for all pool data, and for each location separately using the program IBD (Bohonak 2002). Rousset's distance $\left[F_{\mathrm{ST}} /(1-\right.$ $F_{\text {ST }}$ ] was calculated (Rousset 1997 ) between every pair of rockpools. Geographic distances were calculated using linear map distance (in kilometers). Since F. distichus occupies a narrow band in the intertidal zone, 
we regarded its habitat as linear and did not log transform distances.

Demographic measurements of Fucus distichus populations were made from February 2002 to April 2004. In each pool, we measured $F$. distichus abundance and mean height $(n=10$ random plants per pool). Abundances were either absolute (for pools with low densities) or estimated using $n=4$ quadrats $(25 \times 25 \mathrm{~cm})$ randomly placed within each pool. All abundances were transformed into measures of individuals per $\mathrm{m}^{2}$ by dividing abundance by the surface area of each rockpool. Statistical analyses of changes in abundance within each pool through time were difficult because abundances were often a census of entire pools rather than a sample. Thus, we treated abundance data as a census of each pool and its use is intended as a descriptive measure only. Since we had detailed information on abundances of $F$. distichus in every pool, we were able to identify new recruits (small individuals less than $1 \mathrm{~cm}$ in height) as they appeared. This was done for pools in which adult $F$. distichus occurred in low densities or were absent, because it was impossible to find and identify recruits in pools where adults were abundant. Recruits were sampled in November 2003 in 1 pool from Schoodic (GP pool 5; $n=10$ ) in which adult F. distichus were rare and in November 2003 and April 2004 from 1 pool from Chamberlain (B Pool $1 ; n=6$ in November and $n=2$ in April) in which adults had declined to 3 individuals. In spring 2004 we observed dispersal into SP Pool 1 in the form of a boulder with adult $F$. distichus attached; it had washed into the pool during a storm. Samples were taken from the individuals on this boulder to determine its origin. Three additional pools were also monitored for recruitment, but none was observed.

Experiments on attachment and dispersal of Fucus distichus zygotes. We conducted 2 experiments to test the hypothesis that attachment of Fucus distichus zygotes is delayed in cold temperatures. We predicted that attachment would be delayed as a function of the culture temperature experienced by zygotes as opposed to the temperature at which adults (receptacles) were cultured and gametes released. Fertile receptacles were collected prior to a neap tide in April and in May 2004. Receptacles were returned to the laboratory, immediately placed in seawater and kept in either 5 or $10^{\circ} \mathrm{C}$ incubators on a 12:12 h L:D cycle until release occurred (about noon, 2 d later; see Pearson \& Brawley 1996). The 12:12 $\mathrm{h}$ L:D cycle used in this experiment is similar to natural field conditions in Maine in March and April when this experiment was done. Following release, receptacles were removed, and the fertilized eggs washed in filtered seawater to remove mucilage that is released with the gametes. Equal quantities of the zygote/seawater mixture were poured into plastic petri dishes and incubated at 5, 10 or $15^{\circ} \mathrm{C}$ in the laboratory. The number of attached zygotes was measured at times corresponding to the second $(16 \mathrm{~h})$, third $(28 \mathrm{~h})$ and fourth $(40 \mathrm{~h})$ high tides after release for an initial experiment, and at the third $(14 \mathrm{~h})$, fifth $(38 \mathrm{~h})$ and ninth $(86 \mathrm{~h})$ high tides for a second experiment. These times were the same as the high tides occurring in the field. We replicated the $10^{\circ} \mathrm{C}$ experiment in time to reduce problems of pseudoreplication (Hurlbert 1984) associated with having only 1 incubator per temperature. At each time of sampling, dishes were washed vigorously 3 times with seawater to remove unattached zygotes, fresh seawater was added and the number of attached zygotes was counted in 5 fields of view $\left(\mathrm{FOV}_{;} 0.88 \mathrm{~cm}^{2}\right)$ per dish. Each dish was sampled only once $(n=3$ dishes per time per temperature). Control petri dishes (in which zygotes were left for $5 \mathrm{~d}$ to allow all viable zygotes to attach) were used to estimate initial densities of zygotes. Data were transformed to percentages by dividing counts of attached zygotes per treatment dish with the mean number of zygotes in control dishes. Thus, percentages can be greater than $100 \%$ since densities of zygotes in treatment dishes were occasionally greater than densities in controls and vice versa.

Using results from the above experiments and release and temperature data from the 1995 reproductive season of Fucus distichus (Pearson \& Brawley 1996), we also estimated the potential amount of dispersal of F. distichus from rockpools at Chamberlain in 1995. For days when gamete release occurred, we compared the height of each pool with the height of each high tide following release to determine whether pools were flushed at high tide to permit water exchange among pools. This was done for 5 successive high tides if pools had temperatures $\leq 5^{\circ} \mathrm{C}$ (the majority of pools), or for 3 successive high tides for pools with temperatures between 5 and $10^{\circ} \mathrm{C}$. During the 1995 reproductive season, pool temperature ranged from -4 to $8^{\circ} \mathrm{C}$. Dispersal is possible when the height of the tide exceeded the height of the pool. Thus, we calculated the percentage of days when there was $0,1,2,3$, 4 or 5 chances of dispersal from each rockpool. A 'chance' refers to a high tide where zygotes are still unattached due to low water temperature, and pools are flushed by the tide. Because it is difficult to predict the effects of waves and wind on actual height of the tide, and thus of the amount of water exchange among pools, we did not take this into account in this model. Similarly, since we did not have pool temperature data for every day in the reproductive season, we used the pool temperature on the day of release to determine how long attachment of zygotes was delayed. Thus, we assumed that pool temperature was constant over the 3 to 5 high tide periods examined. 


\section{RESULTS}

\section{Genetic structure of Fucus distichus populations}

Fucus distichus was found to be polymorphic at all 4 loci with 13 (L38), 13 (L20), 8 (L94) and 5 (L58) alleles across all sites (Table 1, Fig. 2). The total number of alleles at each site was similar (Table 1; ANOVA: df: $4,22, \mathrm{p}>0.05)$. Furthermore, there did not appear to be great differences in numbers of alleles among pools within sites, with the exception of GP pool 2, which had 22 alleles (Table 1). There were unique alleles at all sites except Chamberlain A (Table 1) with 3 sites $(\mathrm{BH}, \mathrm{SP}$ and Chamberlain $\mathrm{B})$ having 2 alleles that were found nowhere else and 1 site (GP) having 5 unique alleles. Analyses at the scale of rockpools revealed that 4 of the 5 unique alleles at GP

Table 1. Fucus distichus. Number of individuals sampled and genetic diversity measures for each site and pool at Schoodic $(\mathrm{BH}, \mathrm{SP}, \mathrm{GP})$ and Chamberlain (B, A). Significance levels are shown for $F_{I S}$ values (over all loci). ns: not significant; ${ }^{*} p<$ $0.05 i^{* *} \mathrm{p}<0.01 i^{* * *} \mathrm{p}<0.001$

\begin{tabular}{|c|c|c|c|c|c|c|}
\hline & $n$ & $\begin{array}{c}\text { Total } \\
\text { number } \\
\text { of alleles }\end{array}$ & $\begin{array}{l}\text { Number } \\
\text { of unique } \\
\text { alleles }\end{array}$ & $H_{\mathrm{e}}$ & $H_{\mathrm{o}}$ & $F_{\mathrm{IS}}$ \\
\hline \multicolumn{7}{|l|}{ Site } \\
\hline $\mathrm{BH}$ & 77 & 22 & 2 & 0.542 & 0.241 & $0.56^{* * *}$ \\
\hline SP & 52 & 24 & 2 & 0.570 & 0.322 & $0.45^{* * *}$ \\
\hline GP & 126 & 30 & 5 & 0.532 & 0.200 & $0.63^{* * *}$ \\
\hline B & 40 & 19 & 2 & 0.534 & 0.302 & $0.45^{* * *}$ \\
\hline $\mathrm{A}$ & 41 & 20 & 0 & 0.573 & 0.308 & $0.47^{* * *}$ \\
\hline \multicolumn{7}{|l|}{ Pool } \\
\hline BH 1 & 13 & 15 & 1 & 0.448 & 0.289 & $0.39^{* * *}$ \\
\hline BH 2 & 20 & 14 & 1 & 0.416 & 0.247 & $0.43^{* * *}$ \\
\hline BH 3 & 24 & 17 & 0 & 0.509 & 0.261 & $0.51^{* * *}$ \\
\hline BH 4 & 5 & 7 & 0 & 0.285 & 0.450 & $-0.50^{* * *}$ \\
\hline BH 5 & 15 & 10 & 0 & 0.313 & 0.083 & $0.75^{* * *}$ \\
\hline SP 1 & 5 & 7 & 0 & 0.165 & 0.100 & $0.48^{*}$ \\
\hline SP 2 & 11 & 14 & 2 & 0.496 & 0.355 & $0.33^{* *}$ \\
\hline SP 3 & 20 & 11 & 0 & 0.365 & 0.099 & $0.74^{*}$ \\
\hline SP 4 & 8 & 12 & 0 & 0.541 & 0.558 & $0.04^{\mathrm{ns}}$ \\
\hline SP 5 & 8 & 9 & 0 & 0.452 & 0.689 & $-0.47^{* *}$ \\
\hline GP 1 & 27 & 13 & 0 & 0.434 & 0.307 & $0.31^{* * *}$ \\
\hline GP 2 & 40 & 22 & 4 & 0.547 & 0.250 & $0.55^{* * *}$ \\
\hline GP 3 & 30 & 16 & 0 & 0.268 & 0.094 & $0.66^{* * *}$ \\
\hline GP 4 & 23 & 11 & 0 & 0.381 & 0.130 & $0.67^{* * *}$ \\
\hline GP 5 & 6 & 13 & 1 & 0.486 & 0.292 & $0.48^{* * *}$ \\
\hline B 1 & 5 & 6 & 0 & 0.198 & 0.188 & $0.17^{\mathrm{ns}}$ \\
\hline B 2 & 5 & 7 & 0 & 0.232 & 0.338 & $-0.35^{*}$ \\
\hline B 3 & 6 & 11 & 0 & 0.444 & 0.542 & $-0.13^{\mathrm{ns}}$ \\
\hline B 4 & 24 & 16 & 2 & 0.573 & 0.258 & $0.57^{* * *}$ \\
\hline A 1 & 5 & 10 & 0 & 0.450 & 0.650 & $-0.35^{*}$ \\
\hline A 2 & 25 & 16 & 0 & 0.542 & 0.183 & $0.68^{* * *}$ \\
\hline A 3 & 6 & 10 & 0 & 0.469 & 0.500 & $0.02^{\text {ns }}$ \\
\hline A 4 & 5 & 9 & 0 & 0.500 & 0.300 & $0.49^{* *}$ \\
\hline
\end{tabular}

were all within 1 pool (pool 2; Table 1). There was no evidence of genotyping errors, null alleles, large allele drop out or stuttering when data were checked using Microchecker.

Observed heterozygozities $\left(H_{0}\right)$ for the 5 sites ranged from 0.20 to 0.32 and were significantly lower than expected values for all loci ( $\mathrm{p}<0.01$, Table 1$)$ indicating that across sites Fucus distichus was not in HardyWeinberg equilibrium. The range of observed heterozygosities within rockpools was larger (0.09 to 0.69 ; Table 1). Genetic diversity $\left(H_{\mathrm{e}}\right)$ was similar among sites (0.53 to 0.57$)$ but was highly variable among rockpools $(0.17$ to 0.57$) . F_{\text {IS }}$ estimates within each site were always large (ranging from 0.45 to 0.63 ) and were all found to be statistically different from 0 ( $p<0.01$, Table 1). Similarly, $F_{\text {IS }}$ estimates within each rockpool were often significantly larger than 0 (Table 1) indicating that many pools have an excess of homozygotes (large positive $F_{\text {IS }}$ estimates). A few pools (BH pool 4, SP pool 3, Chamberlain B pool 2 and Chamberlain A pool 1) had large negative $F_{\text {IS }}$ estimates or an excess of heterozygotes.

Patterns produced by a neighbor-joining tree revealed that populations of Fucus distichus at Schoodic are genetically different from those at Chamberlain and group together $88 \%$ of the time (Fig. 3). There was significant genetic differentiation between locations $\left(F_{\mathrm{ST}}=0.146\right)$, among sites $\left(F_{\mathrm{ST}}=0.095\right)$ and among pools $\left(F_{\mathrm{ST}}=0.237\right)$. Interestingly, there was more dissimilarity (pairwise $F_{\mathrm{ST}}=0.05$ ) between the 2 sites at Chamberlain that are separated by only $50 \mathrm{~m}$ than there was among sites within Schoodic that are separated by 0.75 to $2.25 \mathrm{~km}$ (mean pairwise $F_{\mathrm{ST}}$ within Schoodic $=0.026$ ). Pairwise tests between pairs of sites within Schoodic, and between Chamberlain A and B were all non-significant after the Bonferroni correction ( $p<0.0033)$. Tests between sites from opposite locations were mostly significant with the exception of GP, which was genetically similar to Chamberlain B. When analyzing significance levels among pairs of rockpools, we applied the Bonferroni correction by dividing $\mathrm{p}<$ 0.05 with the number of comparisons within each site $(n=10)$. Thus we used a significance level of $\mathrm{p}<0.005$. Most pairwise comparisons with Schoodic sites were significant $(80 \%$ of comparisons at BC, $70 \%$ at SP and $90 \%$ at GP, Table 2). Pools within each site at Chamberlain were not genetically different after the Bonferroni correction (Table 2).

Analyses of molecular variance (AMOVA) found a small (5\%) but significant amount of the total genetic variability was explained between Schoodic and Chamberlain, an insignificant amount of variability among sites within these locations $(<1 \%)$, and most variability within sites $(93 \%$, Table 3$)$. A second AMOVA done at the level of sites and pools revealed 

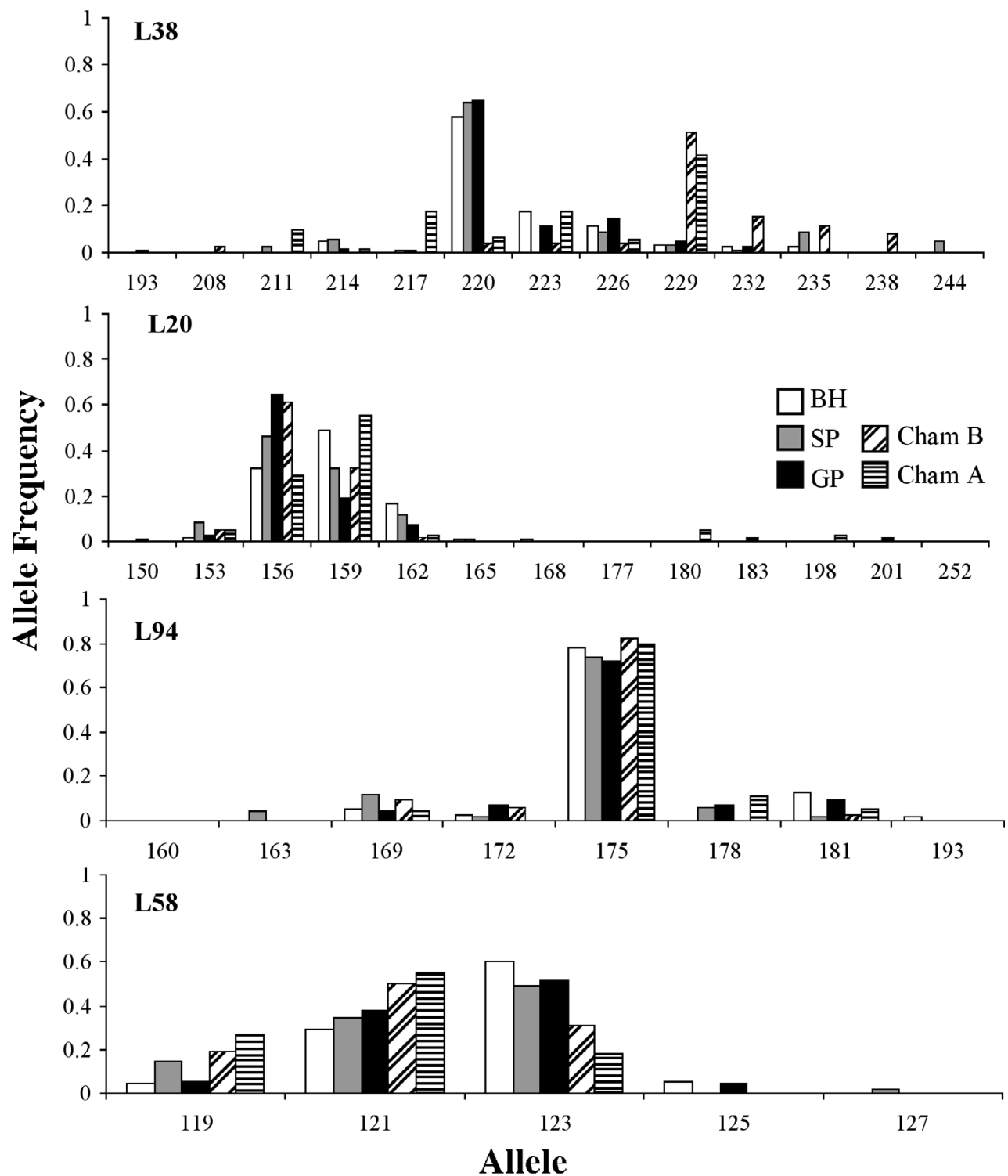

Fig. 2. Fucus distichus. Allele frequencies for all 4 loci at 5 sites. Site abbreviations are as in 'Materials and methods'

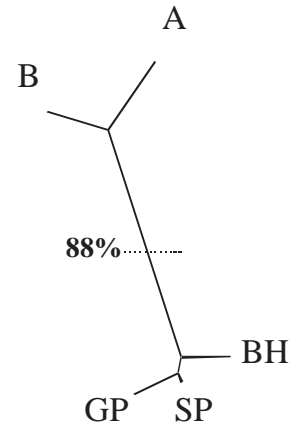

Fig. 3. Fucus distichus. Neighbor-joining tree showing relationships among the 3 sites at Schoodic (GP, SP, BH) and the 2 sites at Chamberlain (A, B). The only bootstrap value greater than $60 \%$ (from 1000 permutations) is indicated by a dotted line. Site abbreviations are as in 'Materials and methods' insignificant variability among sites, a large and significant amount of variability among rockpools within sites $(22 \%)$, and most variability $(75 \%)$ within pools (Table 3). There was a positive correlation between genetic differentiation and linear distances among pools $(Z=2872250.33, \mathrm{r}=0.28, \mathrm{p}<0.01)$.

\section{Demography of Fucus distichus}

Densities of Fucus distichus varied greatly between Schoodic and Chamberlain. There were up to 80 individuals $\mathrm{m}^{-2}$ at Schoodic and an average of only 5 individuals $\mathrm{m}^{-2}$ at Chamberlain (Fig. 4). In addition, densities within each rockpool were variable through time 


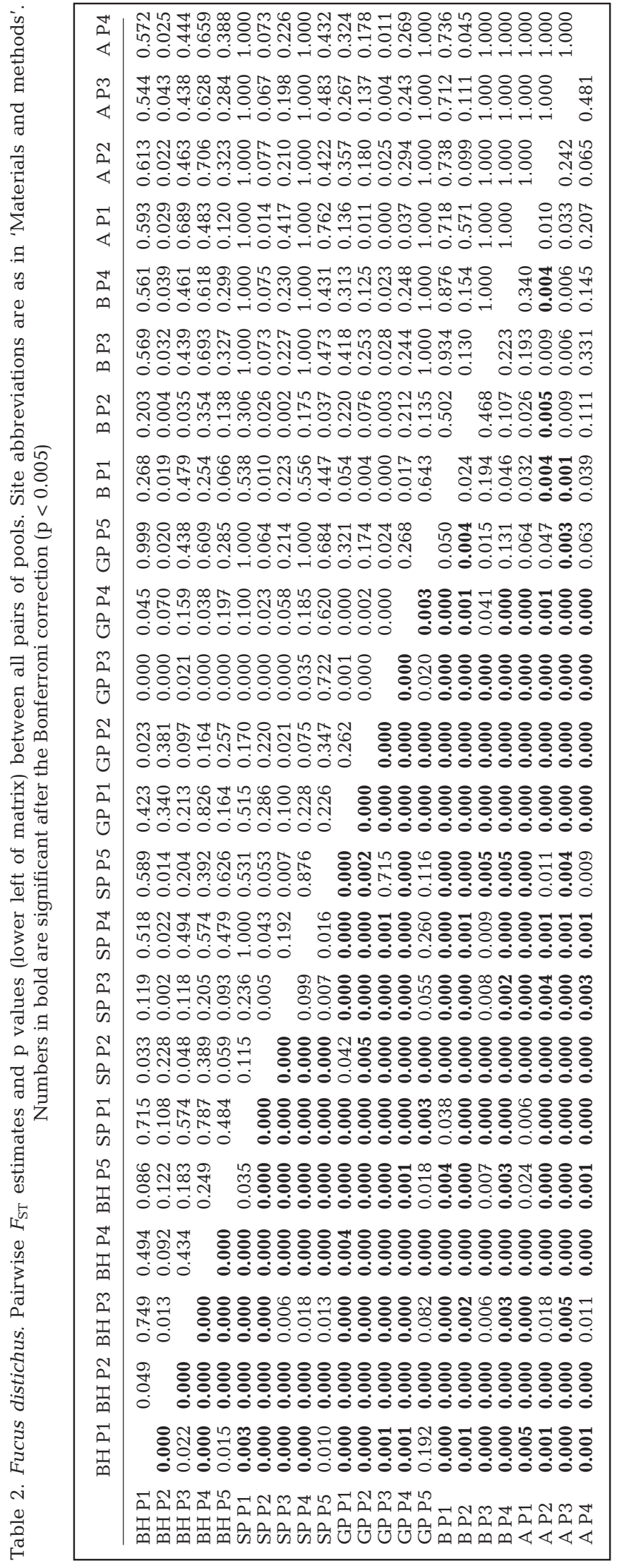

Table 3. Fucus distichus. Analyses of molecular variance (AMOVA) for locations and sites within locations, and sites and pools within sites. SS: sum of squares; ns: not significant; ${ }^{* * *} \mathrm{p}<0.001$

\begin{tabular}{|lrrrc|}
$\begin{array}{l}\text { Source of } \\
\text { variation }\end{array}$ & df & SS & $\begin{array}{c}\text { Variance } \\
\text { component }\end{array}$ & $\begin{array}{c}\text { Variation } \\
(\%)\end{array}$ \\
\hline \multicolumn{2}{l}{ Among and within locations } \\
$\begin{array}{l}\text { Among locations } \\
\begin{array}{l}\text { Among sites } \\
\quad\end{array}\end{array}$ & 1 & 8.33 & 0.030 & $5.95^{* * *}$ \\
$\quad \begin{array}{l}\text { within locations } \\
\text { Within sites }\end{array}$ & 667 & 315.20 & 0.473 & $93.24^{* * *}$ \\
$\begin{array}{l}\text { Among and within sites } \\
\text { Among sites }\end{array}$ & 4 & 54.48 & 0.032 & $2.95^{\mathrm{ns}}$ \\
$\begin{array}{l}\text { Among pools } \\
\quad \text { within sites }\end{array}$ & 18 & 129.39 & 0.238 & $22.00^{* * *}$ \\
Within pools & 649 & 527.21 & 0.812 & $75.04^{* * *}$ \\
\hline
\end{tabular}

and extinctions were observed in at least 1 pool (Chamberlain A P4, Fig. 4). Some pools experienced great declines in abundance (Chamberlain A pool 1, Chamberlain B pool 3, SP pool 4) with abundances in 1 pool (GP pool 5) declining by $80 \%$ (Fig. 4). All pools recovered from declines in abundance, although some at a slow rate (e.g. SP pool 4).

Patterns in the mean size of Fucus distichus in pools were dynamic due to the combined effects of growth, new recruitment, and regrowth after plants were cropped by ice during winter. At Chamberlain A, the size of $F$. distichus in pools generally increased or remained relatively constant (Fig. 5) except in pool 4, where $F$. distichus became extinct in spring 2003. The size of $F$. distichus in all pools at Chamberlain B steadily increased over time but decreased at the spring 2004 sampling period (Fig. 5). This appeared to be due to cropping of algae from ice damage during winter. At SP, the size of plants in pools 3 and 4 remained relatively constant. In pool 4 , mean size increased until spring 2003, then decreased as recruitment occurred in this pool. Mean size of individuals in all pools at GP was relatively constant throughout the sampling period (Fig. 5).

\section{Dispersal of Fucus distichus}

The percentage of adult Fucus distichus that were assigned to a rockpool other than the one in which they were growing, and that could be considered to be first generation migrants varied among pools (Fig. 6). The percentage of individuals within each pool that were residents varied between 0 and $80 \%$ (Fig. 6). Individuals that were migrants were often 
assigned to another site and sometimes to another location (Fig. 6). Assignment tests to determine the likely origin of $F$. distichus recruits found that none of the Chamberlain B recruits were assigned to the pool in which they were growing in November, but the 2 recruits sampled in April 2004 were (Table 4). Recruits sampled in November had genotypes that were similar to pools 2 and 3 (approximately 1 and $3 \mathrm{~m}$ away, respectively). In contrast, $70 \%$ of recruits at GP were assigned to the pool in which they were growing (Table 4). The remaining 30\% were assigned to pool 4 (the closest neighboring pool; $11 \mathrm{~m}$ across a bare rock platform). The F. distichus that was found on the boulder washed into SP pool 1 was found to have come from the closest neighboring pool (pool 2, 2 m away and lower on the shore, Table 4).
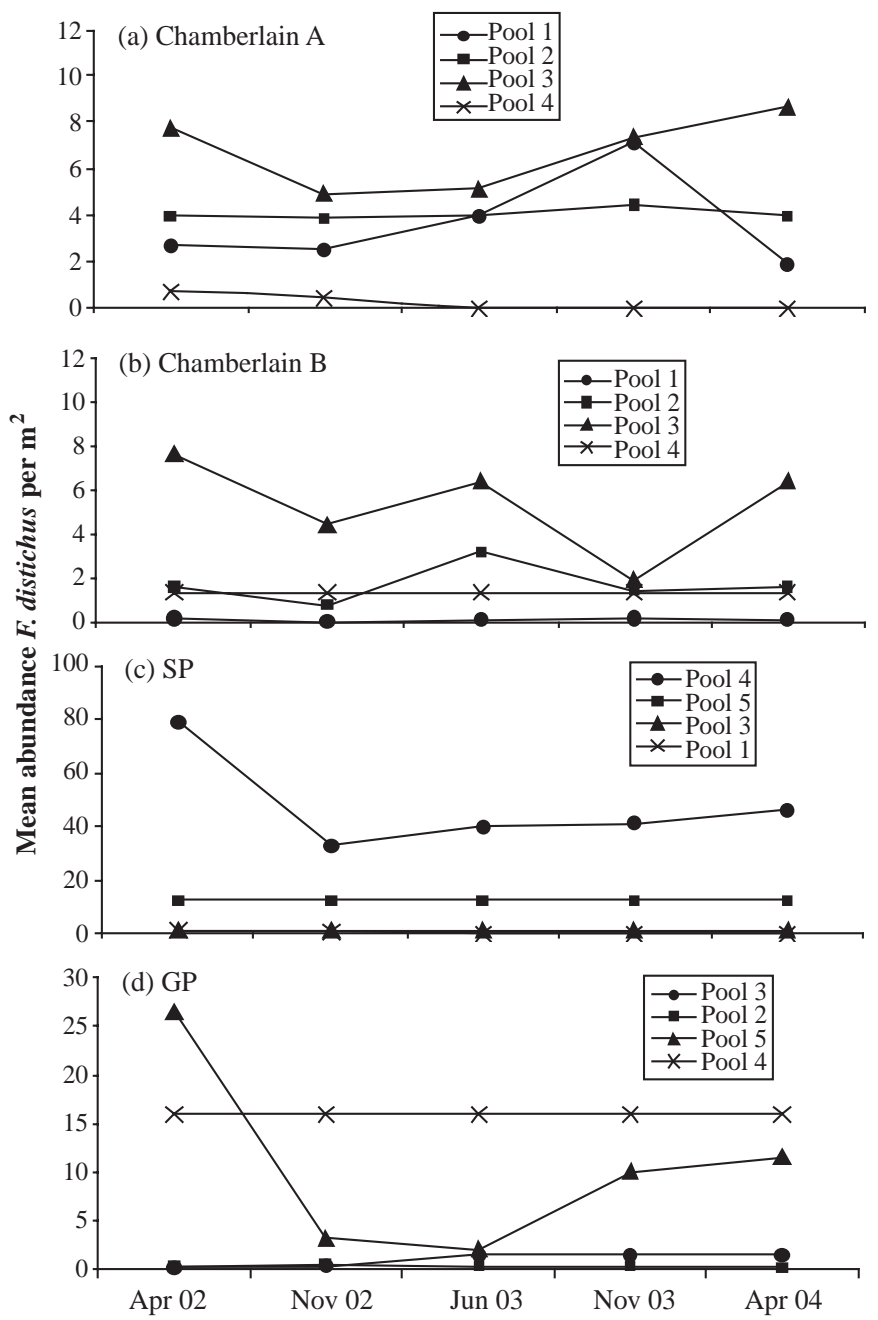

Fig. 4. Fucus distichus. Densities of populations within pools at 4 sites from Spring 2002 to Spring 2004. Values are either absolute or an average from $n=4$ quadrats per pool per time (see 'Materials and methods')

\section{Effects of temperature on attachment and dispersal of zygotes}

Regardless of the temperature at which receptacles were incubated prior to gamete release, attachment was delayed when zygotes were kept at $5^{\circ} \mathrm{C}$ relative to 10 or $15^{\circ} \mathrm{C}$ (Table 5, Fig. 7). This pattern was consistent at all times in the first experiment (Table 5, Fig. 7a), but varied among times in the second experiment. In the second experiment, rates of attachment of zygotes among temperatures at each time were consistent between the 5 and $10^{\circ} \mathrm{C}$ temperatures of receptacle incubation. After the third high tide, attachment was delayed at $5^{\circ} \mathrm{C}$ compared to $10^{\circ} \mathrm{C}$, and $10^{\circ} \mathrm{C}$ relative to $15^{\circ} \mathrm{C}$. At the fifth high tide, attachment was similar at 10 and $15^{\circ} \mathrm{C}$, but slower at $5^{\circ} \mathrm{C}$ (although this is not
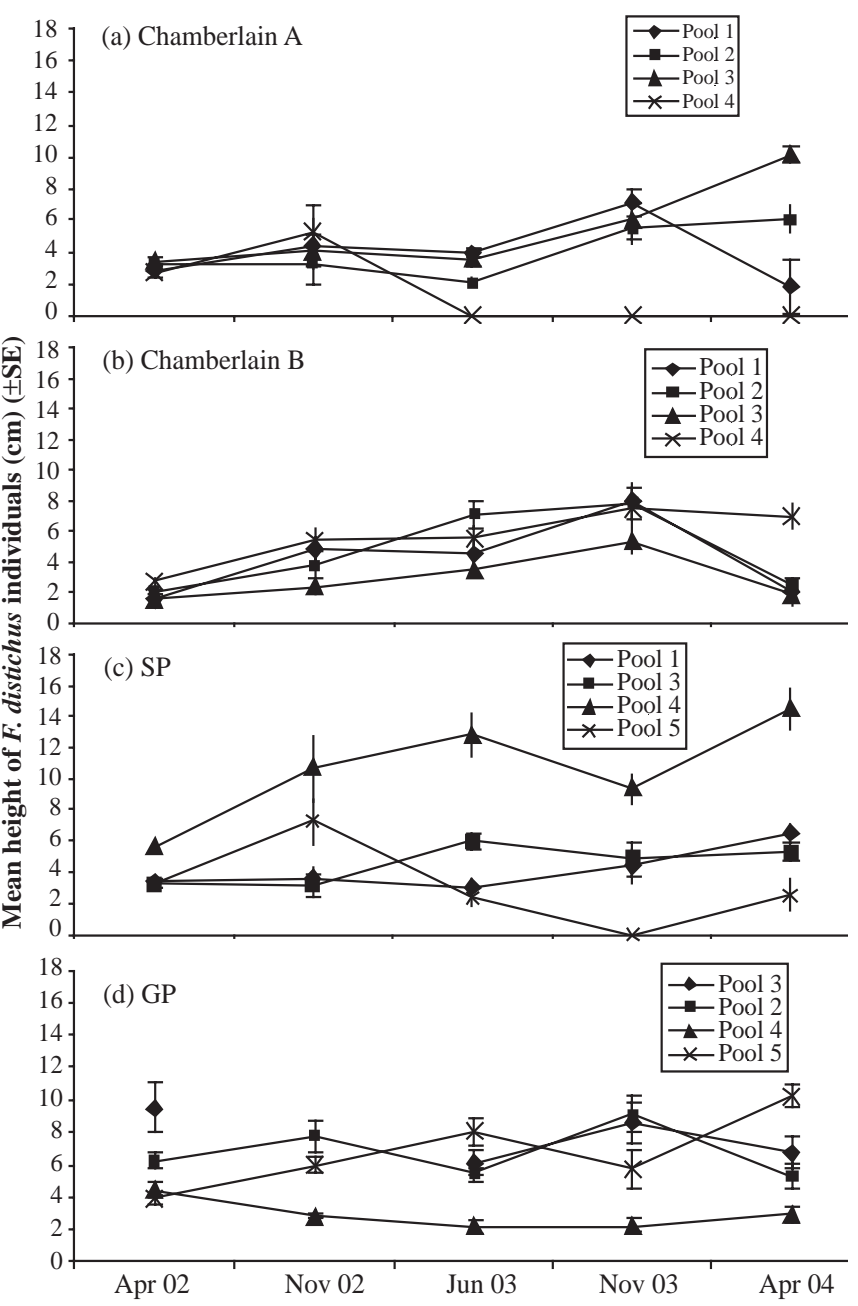

Fig. 5. Fucus distichus. Mean height $(\mathrm{cm})$ of individuals within pools at 4 sites from Spring 2002 to Spring 2004. $n=10$ individuals per pool per time 


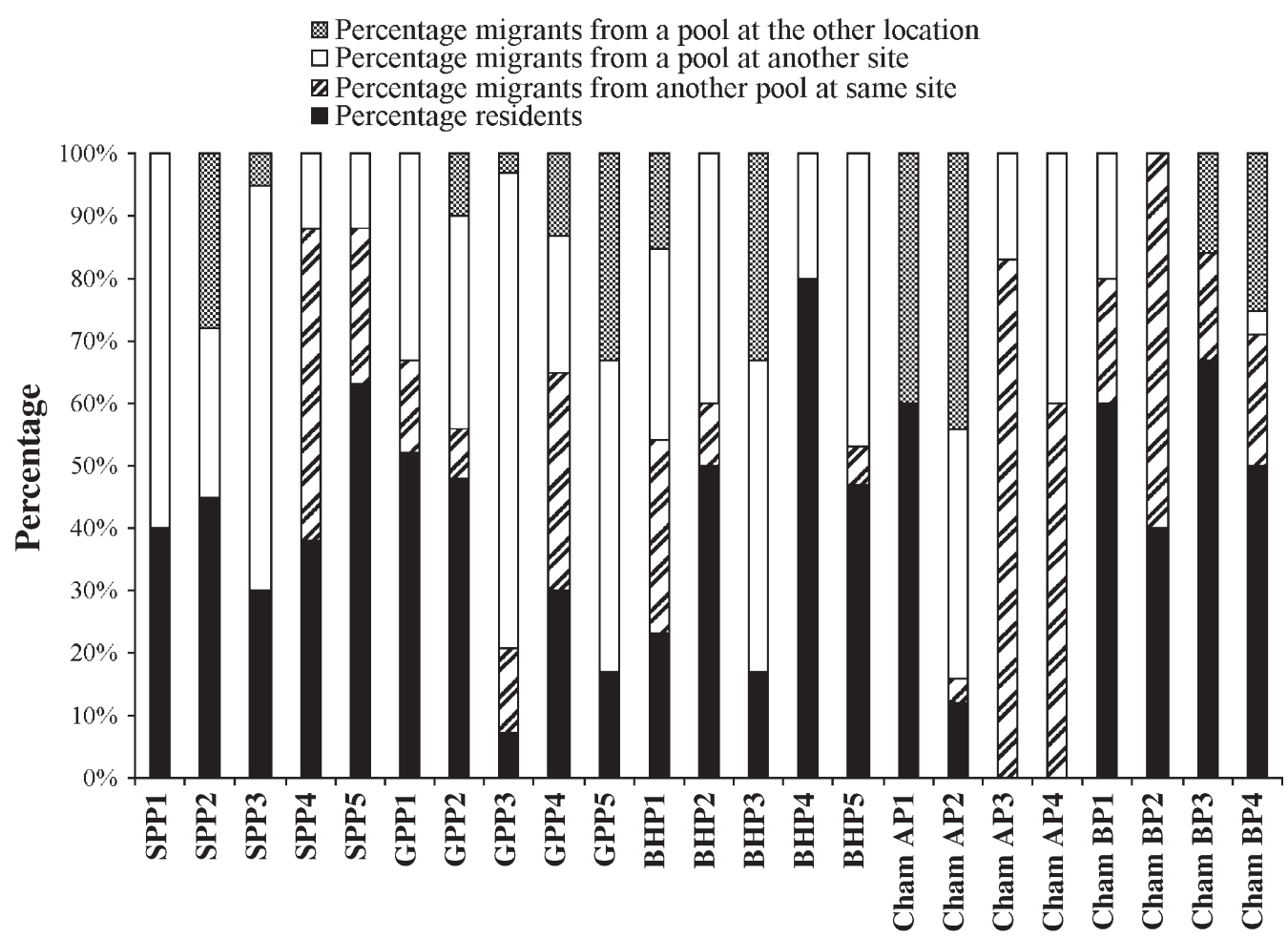

Fig. 6. For each rockpool, the percentage of all adult Fucus distichus that were assigned as 1st generation migrants from the pool from which they were sampled (residents), another pool at the same site, a rockpool at another site at the same point or a rockpool at the other location. Number of individuals sampled per pool is given in Table 1

represented in Fig. $7 \mathrm{c}$ ). At the final time of sampling (the ninth high tide) attachment was similar among temperatures. Interestingly, regardless of the temperature at which zygotes were cultured, attachment was delayed when receptacles were incubated (until gamete release) at $5^{\circ} \mathrm{C}$ compared to $10^{\circ} \mathrm{C}$ (significant TR term in Table 5, Expt 2).

The number of chances that Fucus distichus had to disperse during the 1995 reproductive season varied among times and among pools (Figs. 8 \& 9). Although peaks in gamete release were centered around neap tides (approximately \pm 2 d), some gamete release occurred closer to spring tides (Pearson \& Brawley 1996). Release on either side of a neap tidal series is likely due to stochasticity in factors such as weather, and the time of low tide relative to sunrise (Pearson \& Brawley 1996, Serrão et al. 1996, Pearson et al. 1998). Dispersal in our model generally became more variable and less frequent towards the end of the reproductive season. During the March 9 neap tide, there was almost no chance for dispersal from any pool except pool 1 at Chamberlain A (Figs. 8 \& 9). Further, algae that released gametes in most pools during the February 22 neap tide would also have experienced a decrease in the number of chances for dispersal (Figs. 8 \& 9). When small amounts of release occurred close to spring tides,
Table 4. Assignment tests on Fucus distichus recruits from Chamberlain site B and Schoodic site GP and adults that were found growing on a rock washed into a pool at Schoodic site SP. Analyses were done using data from the site in which the recruit or adult was found. Percentage assignment was calculated from 1000 permutations

\begin{tabular}{|llc|}
\hline $\begin{array}{l}\text { Pool in which } \\
\text { recruits }\end{array}$ & $\begin{array}{l}\text { Pool of } \\
\text { likely } \\
\text { origin }\end{array}$ & $\begin{array}{c}\text { Assignment } \\
\text { to likely pool } \\
\text { of origin (\%) }\end{array}$ \\
\hline Cham B P1 recruit 1 & Cham B P3 & 99.05 \\
Cham B P1 recruit 2 & Cham B P3 & 70.54 \\
Cham B P1 recruit 3 & Cham B P4 & 79.50 \\
Cham B P1 recruit 4 & Cham B P3 & 91.75 \\
Cham B P1 recruit 5 & Cham B P4 & 83.33 \\
Cham B P1 recruit 6 & Cham B P3 & 57.89 \\
Cham B P1 recruit 7 (2004) & Cham B P1 & 99.84 \\
Cham B P1 recruit 8 (2004) & Cham B P1 & 93.85 \\
GP P5 recruit 1 & GP P4 & 51.75 \\
GP P5 recruit 2 & GP P5 & 96.74 \\
GP P5 recruit 3 & GP P5 & 65.15 \\
GP P5 recruit 4 & GP P5 & 90.63 \\
GP P5 recruit 5 & GP P5 & 80.16 \\
GP P5 recruit 6 & GP P5 & 59.85 \\
GP P5 recruit 7 & GP P5 & 96.57 \\
GP P5 recruit 8 & GP P4 & 91.29 \\
GP P5 recruit 9 & GP P4 & 91.77 \\
GP P5 recruit 10 & GP P5 & 97.99 \\
SP P1 boulder individual 1 & SP P2 & 90.30 \\
SP P1 boulder individual 2 & SP P2 & 76.33 \\
\hline
\end{tabular}


Table 5. Analyses of variance (ANOVA) for attachment experiments. $n=3$ petri dishes per time per temperature. All factors were orthogonal to each other and fixed. ${ }^{*} \mathrm{p}<0.05_{;}{ }^{* *} \mathrm{p}<0.01 ;{ }^{* * *} \mathrm{p}<0.001$. (a) Time $1: 5^{\circ} \mathrm{C}<10^{\circ} \mathrm{C}<15^{\circ} \mathrm{C} ;$ Time $2: 5^{\circ} \mathrm{C}<10^{\circ} \mathrm{C}=15^{\circ} \mathrm{C}$; Time 3: not significant

\begin{tabular}{|c|c|c|c|c|}
\hline Source & df & MS & $F$ & Post-hoc test \\
\hline \multicolumn{5}{|l|}{ Expt 1} \\
\hline Temperature of zygotes incubation & 2 & 2910.69 & $18.85^{* * *}$ & $5^{\circ} \mathrm{C}<10^{\circ} \mathrm{C}=15^{\circ} \mathrm{C}$ \\
\hline Time after release & 2 & 4071.63 & $26.37^{* * *}$ & $\mathrm{~T} 1<\mathrm{T} 2=\mathrm{T} 3$ \\
\hline Temperature $\times$ Time & 4 & 347.84 & 2.25 & \\
\hline Residual & 18 & 154.39 & & \\
\hline \multicolumn{5}{|l|}{ Expt 2} \\
\hline Temperature of receptacle incubation (TR) & 1 & 3847.75 & $18.41^{* * *}$ & $10^{\circ} \mathrm{C}>5^{\circ} \mathrm{C}$ \\
\hline Temperature of zygote incubation (TZ) & 2 & 2249.58 & $10.76^{* * *}$ & $5^{\circ} \mathrm{C}<10^{\circ} \mathrm{C}=15^{\circ} \mathrm{C}$ \\
\hline Time after release & 2 & 11411.81 & $54.6^{* * *}$ & $\mathrm{~T} 1<\mathrm{T} 2=\mathrm{T} 3$ \\
\hline $\mathrm{TR} \times \mathrm{TZ}$ & 2 & 894.88 & 4.28 & \\
\hline TR $\times$ Time & 2 & 725.64 & 3.47 & \\
\hline $\mathrm{TZ} \times$ Time & 4 & 1252.67 & $5.99^{* *}$ & see (a) in legend \\
\hline $\mathrm{TR} \times \mathrm{TZ} \times$ Time & 4 & 464.61 & 2.22 & \\
\hline Residual & 36 & 209.02 & & \\
\hline
\end{tabular}

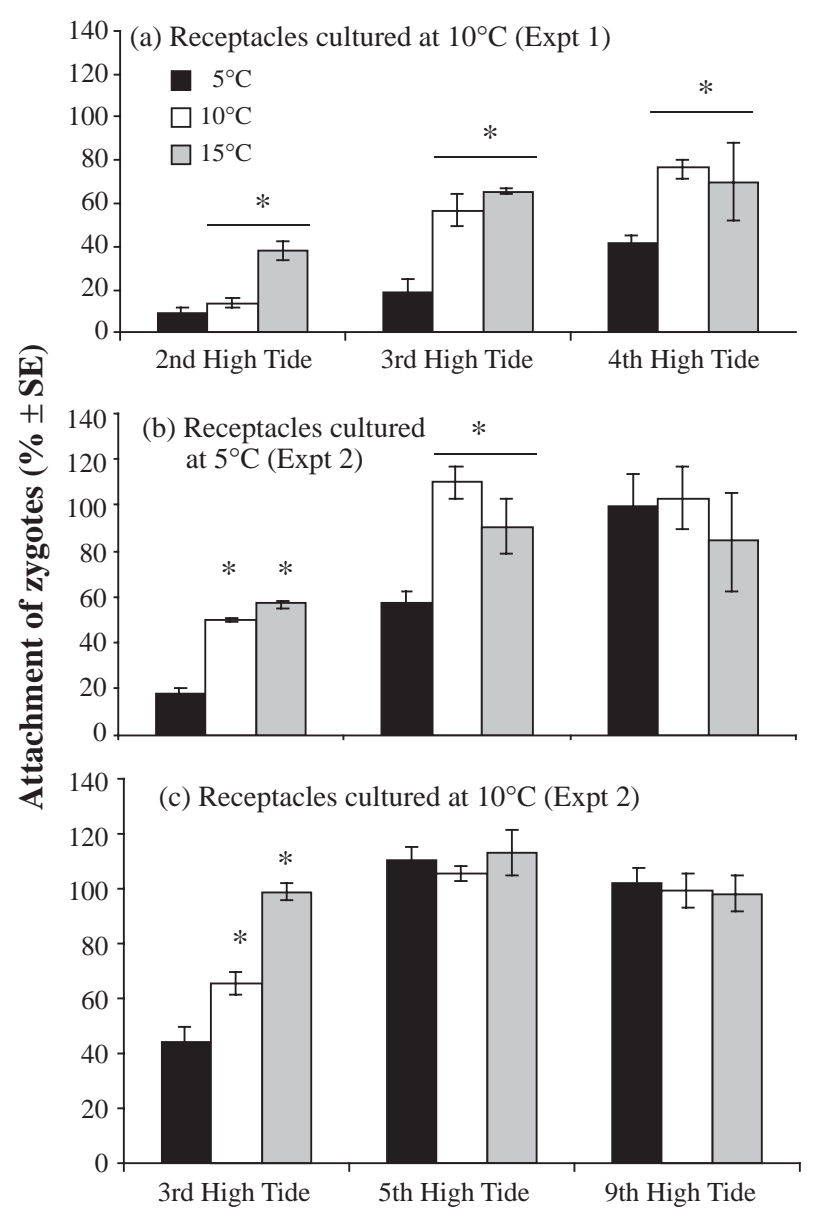

Fig. 7. Fucus distichus. Percentage attachment of zygotes from adults (receptacles) cultured and gametes released at (a) $10^{\circ} \mathrm{C}\left(\right.$ Expt 1), (b) $5^{\circ} \mathrm{C}\left(\right.$ Expt 2) and (c) $10^{\circ} \mathrm{C}$ (Expt 2) and cultured at 5, 10 and $15^{\circ} \mathrm{C}$ post-fertilization. See 'Materials and methods' for exact times (h). There were $n=3$ petri dishes per time per temperature and $n=5$ random fields of view sampled per dish. $* p<0.05$ there were always 5 or more chances for dispersal. Rockpools at Chamberlain A generally appeared to have fewer chances for dispersal than those at Chamberlain B. This is because Chamberlain A pools are positioned higher on the shore (3.2 $\mathrm{m}$ above MLW) than those at site B (2.7 to $3 \mathrm{~m}$ ).

\section{DISCUSSION}

\section{Restriction of dispersal and genetic structure}

Just as wind and water can be important agents of dispersal in terrestrial systems, currents and water motion are the primary mode of dispersal in sessile marine organisms (Palumbi 1994, Grosberg \& Cunningham 2001). Because Fucus distichus relies on the passive action of waves and currents to disperse sperm and zygotes, pools must lie close to each other for water to be exchanged between them. As predicted, populations of $F$. distichus were highly differentiated at a number of spatial scales (hundreds of $\mathrm{km}$ to pools separated by 10 s of $\mathrm{cm}$ ) and a significant positive correlation was found between genetic differentiation and distance between pools. These results suggest that dispersal in $F$. distichus can be restricted because water exchange among pools is often not sufficient to facilitate frequent dispersal of zygotes on scales greater than a few meters. Indeed, when dispersal was observed, recruits most likely came from neighboring pools (Table 4). In a study on similar spatial scales, Marshall et al. (2004) found dispersal of gametes of the rockpool anemone Oulactis mucosa to be greatly restricted among pools separated by as little as one meter because intermittent wave splash was the only mode of dispersal. 
6 (a) Chamberlain A, Pool 1
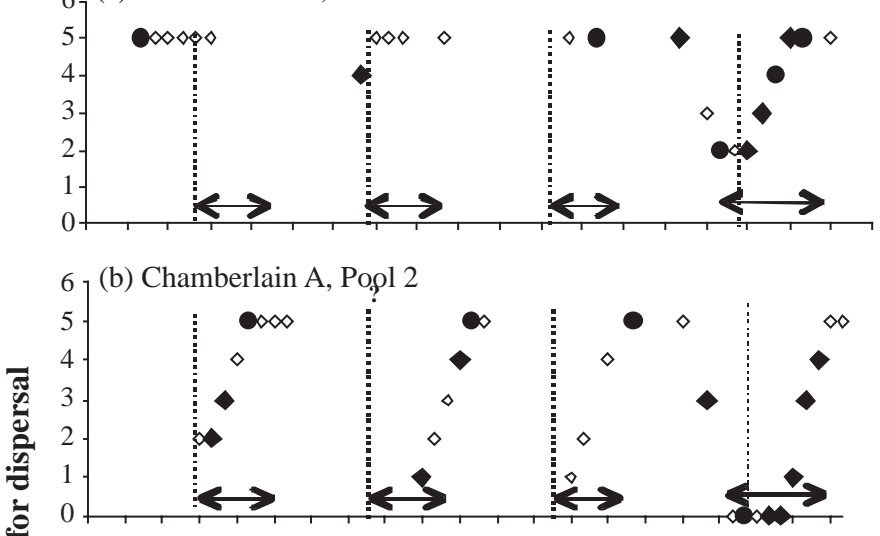

(c) Chamberlain A, Pool 3

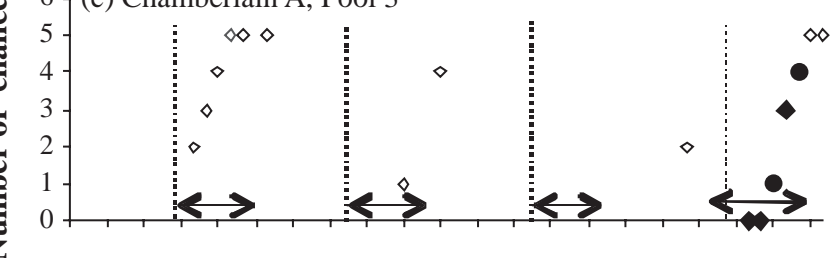

6 (d) Chamberlain A, Pool 4

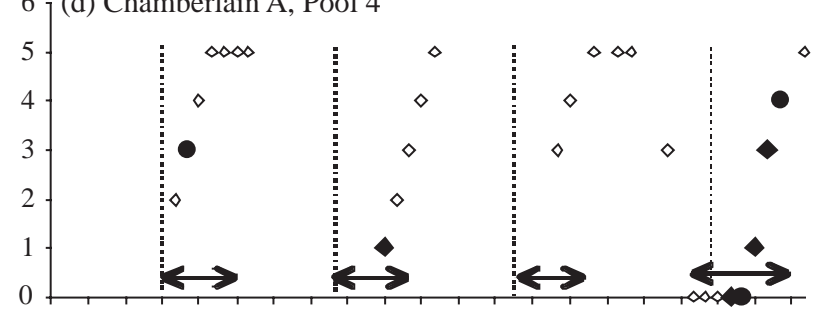

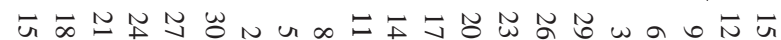

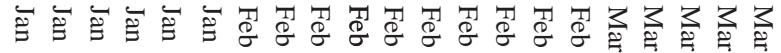

Date on which gamete release was observed (1995)

Fig. 8. Fucus distichus. The number of chances for dispersal from each pool at Chamberlain A for zygotes that were produced on each day that release occurred in the 1995 reproductive season. For example, 5 chances means that a zygote produced on that particular day during the reproductive season can potentially disperse for up to 5 high tides following release. Different symbols indicate the amount of release on that day; $\diamond$ : days when release was small $\left(<10\right.$ eggs $\left.\mathrm{cm}^{-2}\right)$, $\bullet$ : days when release was intermediate (between 10 and 100 eggs $\left.\mathrm{cm}^{-2}\right) ;$ Pearson \& Brawley 1996). Dotted lines indicate the day on which neap tides occurred. Arrows indicate days on which low tides fell between $10 \mathrm{am}$ and $3 \mathrm{pm}$ (thus, there was enough daylight for gamete release to occur). Sampling was not done between Jan 31-Feb 10 and Feb 17-Feb 21

Even when distances among patches of habitat do not exceed the spatial scale on which the organisms have the ability to disperse, dispersal among patches can be directly or indirectly restricted by the presence of physical barriers (e.g. Mader 1984, Neraas \& Spruell 2001, Gilg \& Hilbish 2003, Won et al. 2003). For Fucus distichus, the topography of substrata that separates
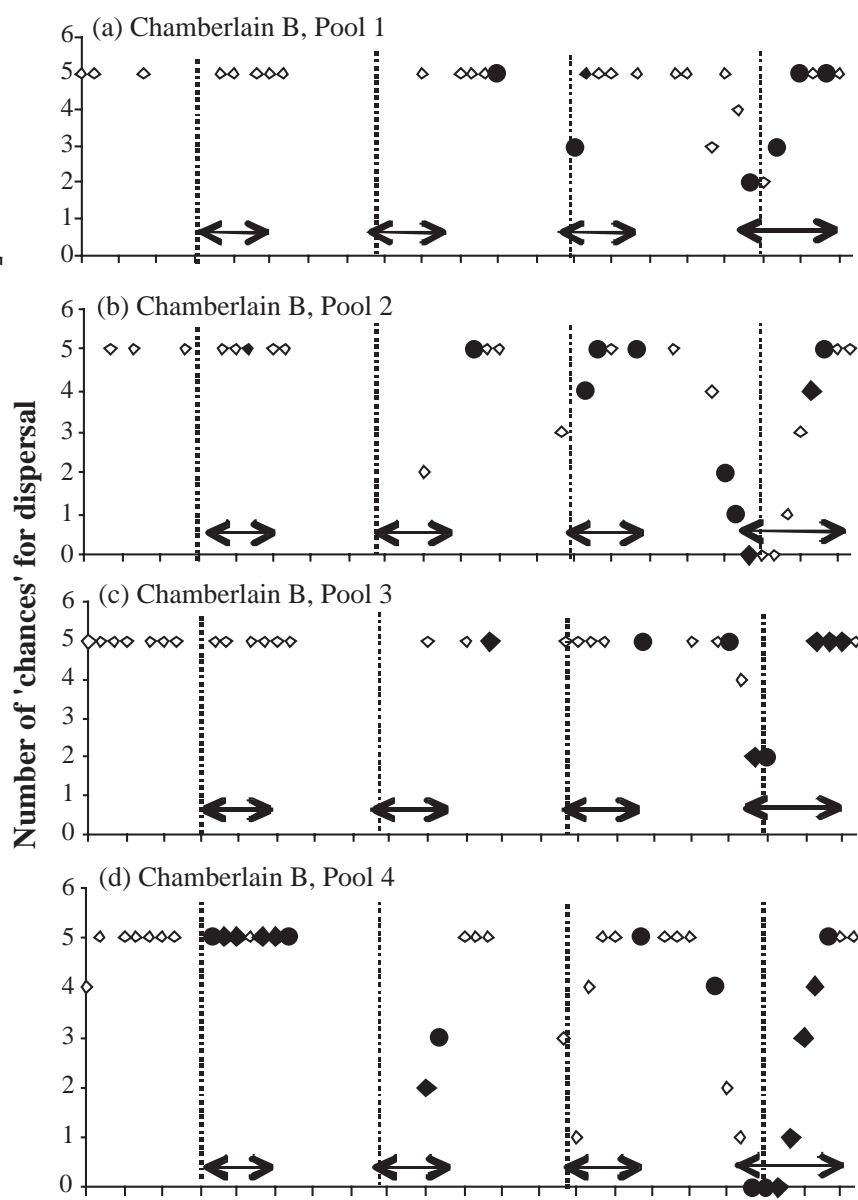

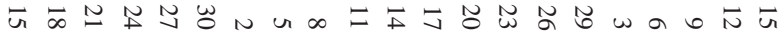

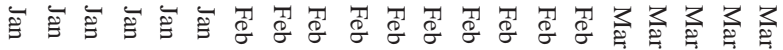

Date on which gamete release was observed (1995)

Fig. 9. Fucus distichus. The number of chances for dispersal from each pool at Chamberlain B for each day that release occurred in the 1995 reproductive season. See Fig. 8 for explanation of symbols. Sampling was not done between Jan 31-Feb 10 and Feb 17-Feb 21

rockpools may contribute to the high levels of genetic differentiation by presenting physical barriers that restrict dispersal of gametes and zygotes. Preliminary studies using fluorescein dye to track the movement of water among pools indicated that elevated rock dikes and the slope of rock between pools act as barriers that can limit the exchange of water among neighboring pools. Similarly, the slope of rock between pools was observed to influence the amount and direction of dispersal of $F$. distichus zygotes. This was also found for the alga Gracilaria gracilis (Engel et al. 2004), where dispersal is restricted by the flow of water from high to low shore pools.

High levels of differentiation among populations may also be due to extinction and recolonization events 
when dispersal into unoccupied patches of habitat is from one or a few source populations (Wade \& McCauley 1988). This may contribute to observed patterns of genetic diversity of Fucus distichus over short (1 to 2 yr) time scales (Whitlock 1992). For example, recolonization of pools in which there was no Fucus distichus was from neighboring pools (Table 4), and recruitment in pools in which $F$. distichus was rare was from a neighbor, or from the same pool. Thus, over short time scales, such founder effects may lead to population differentiation that is greater than if colonists came from multiple sources. However, given that extinction was relatively infrequent during the course of this study (Fig. 4), and that long distance dispersal appeared to be common in past generations (Table 5), we find it unlikely that this is a major factor contributing to long-term population dynamics. Largescale extinctions and massive declines in abundances do occur, and have been observed at 2 sites (Chamberlain A and B) in the past (approximately 2000, S. H. Brawley pers. obs.; compare Chamberlain pool densities in Pearson \& Brawley [1996] with those given here). Indeed, founder effects may explain why there was little differentiation among pools within these sites, but differentiation between the 2 sites was high. Despite being only $50 \mathrm{~m}$ apart, the 2 sites at Chamberlain were more genetically different from one another $\left(F_{\mathrm{ST}}=\right.$ 0.049) than sites at Schoodic were to each other (average pairwise $F_{\mathrm{ST}}$ between Schoodic sites $=0.026$ ). Differences between the 2 Chamberlain sites may have arisen if the sites were colonized from different sources following the 2000 extinction event.

Although there are few studies that test hypotheses on spatial scales as small as those here (pools separated by as little as $30 \mathrm{~cm}$ ), population genetic differentiation of Fucus distichus appears to be great compared to other intertidal algae. For example, the related Silvetia compressa (= formerly Pelvetia fastigiata) is also monoecious, and releases gametes at low tide. As with F. distichus, this species exhibits high genetic structure among reefs separated by at least $3 \mathrm{~m}$ (Williams \& Di Fiori 1996) and $99 \%$ of genetic variation was explained among individuals within reefs (Williams \& Di Fiori 1996). In contrast, populations of the congeneric species F. serratus (Coyer et al. 2003) and F. spiralis (Coleman \& Brawley in press) show little differentiation on small spatial scales (hundreds of meters to kilometers). Perhaps the great differentiation in populations of $F$. distichus relative to other algae is largely determined by its rockpool habitat. High levels of differentiation among populations of rockpool species has also been found for the intertidal snail Bembicium vittatum (Johnson \& Black 1998), and the rockpool copepod Tigriopus californicus (among pools separated by tens of meters, Burton \& Feldman 1981). Indeed, genetic variability among tidepool populations of $B$. vittatum was substantially greater than among non-tidepool populations inhabiting adjacent shores (Johnson \& Black 1998). Although caution must be taken when making comparisons among studies that utilize different genetic marker systems, these studies demonstrate that rockpools, even when separated by large distances, are habitats that are conducive to the formation of strong genetic structure.

\section{Selfing and low genetic diversity within rockpools}

Populations of Fucus distichus in most pools were characterized by an excess of homozygotes. There are a number of mechanisms that may cause this observed pattern. First, given that $F$. distichus is monoecious and releases gametes into isolated, calm bodies of water (Pearson \& Brawley 1996) where there is potentially little mixing of gametes, we hypothesize that selfing within many pools is common. This is even more likely given the rapid rate of fertilization of $F$. distichus eggs (Pearson \& Brawley 1996). We consider this to be the most likely mechanism responsible for the observed levels of homozygosity within pools. Nevertheless, determining relative levels of selfing versus outcrossing within rockpools would require detailed parentage analysis of zygotes. Another possibility is that inbreeding may be common within some pools, particularly those that are higher on the shore, far from other pools, or separated by some 'barrier' to dispersal. We consider it unlikely, however, that inbreeding plays a major role in determining observed heterozygote deficiencies in most rockpools, because dispersal among pools appears to be a frequent event. Third, it is possible that selection for homozygotes is occurring in pools. Selection is likely given the wide range of physical and biological conditions among rockpools (depth, salinity, temperature, predation etc), which may produce different selective pressures on individuals inhabiting each pool. For this to be true, homozygotes must have some fitness advantage (e.g. greater growth rates to escape predation, greater tolerance of extreme temperatures). This would require the ambitious assumption, however, that the neutral microsatellite markers used here are linked to regions of the genome under selection. Finally, the deficiency of heterozygotes within many rockpools and within all sites may be caused by a Wahlund effect (Wahlund 1928), where $F_{\text {IS }}$ estimates are elevated as a result of expected heterozygosities being estimated assuming that samples are drawn from one panmictic population. This might explain large $F_{\text {IS }}$ estimates for each site, but we find it unlikely that there are subpopulations within each rockpool, particularly since not all pools exhibited het- 
erozygote deficiencies (Table 1). Nevertheless, careful consideration should be given to the possibility of Wahlund effects in all genetic studies. For most marine organisms, habitat subdivision is often not as discrete or obvious as it is here (rockpools). Where possible, sampling designs should utilize a priori knowledge of population differentiation to avoid sampling over more than one genetic population.

\section{A novel mechanism of dispersal among pools}

Despite high population differentiation among rockpools, dispersal of Fucus distichus among rockpools was frequently observed to occur via recruitment of juveniles. Contrary to predictions, this is likely to be a common occurrence, because between 20 and $100 \%$ of adults were identified as first generation migrants from another pool, suggesting high levels of gene flow. This result was surprising given the timing of reproduction of $F$. distichus (low, neap tides) and the patchy nature of its habitat (rockpools). Interestingly, we found that the reproductive seasonality of this species greatly enhanced its ability to disperse because of the slow attachment of zygotes to substrata at the cold temperatures that prevail during the $F$. distichus reproductive season. Although F. distichus releases gametes at low tide when there is little water exchange among pools, zygotes have the ability to disperse for up to 5 high tides (approximately $50 \mathrm{~h}$ ) after fertilization, depending on the temperature within pools. Thus, even if pools are isolated from bulk seawater on the high tide immediately following release, dispersal of zygotes is still possible on subsequent high tides when there may be exchange of water among pools. Both the low sperm:egg ratio of monecious fucoids and gamete longevity favor the higher than expected dispersal of $F$. distichus occurring mainly through continued dispersal of unattached zygotes versus from gametes (Brawley 1991, Serrão et al. 1999a).

The delay in attachment of zygotes at cold temperatures may influence temporal variability in the amount of gene flow among populations. At $14^{\circ} \mathrm{C}$, fucoid zygotes begin to secrete adhesive wall polymers at $4 \mathrm{~h}$ post-fertilization and adhere to surfaces by $6 \mathrm{~h}$ postfertilization (Kropf 1992). Thus in spring, zygotes are likely to attach to the substratum relatively quicker, and have fewer opportunities to disperse, compared to winter. This may have important genetic consequences for populations of Fucus distichus, particularly if there are discrete winter- versus spring-reproducing individuals or populations. Annual variability in dispersal can alter patterns of gene flow in terrestrial plant communities (Moran \& Brown 1980, Murawski \& Hamrick 1991) but to our knowledge, there are no accounts of heterogeneity in dispersal within a single reproductive season (Figs. 8 \& 9). The increased potential for dispersal in cold temperatures may also have consequences for the long-term persistence of $F$. distichus, particularly in northern New England, which is the southern edge of its range (Sears 2002). With continued global warming and rising sea temperatures, $F$. distichus may experience fewer chances for dispersal each reproductive season, potentially leading to greater inbreeding.

There is much debate as to whether dispersal in fragmented or patchy habitats is selected for (Thomas et al. 1998, Hill et al. 1999) or against (Cody \& Overton 1996, Hanski et al. 2002). Some organisms exhibit greater potential for dispersal in habitats that are highly fragmented (Thomas et al. 1998, Hill et al. 1999). Moreover, in at least 1 species (the butterfly Hesperia comma), characteristics that enhance dispersal have a genetic basis (Hill et al. 1999). We hypothesize that reproducing in winter-early spring may be a mechanism that Fucus distichus evolved as a consequence of the reproductive isolation associated with releasing gametes into isolated bodies of water during low, neap tides. As with other fucoid algae, the timing of release of gametes of $F$. distichus is dependent upon photosynthetic metabolism under calm conditions (Serrão et al. 1996, Pearson et al. 1998) and these factors result in fertilization success close to $100 \%$ (Pearson \& Brawley 1996). Nevertheless, this also means that zygotes cannot disperse for at least $6 \mathrm{~h}$ and sometimes as long as $3 \mathrm{~d}$ after fertilization due to isolation of pools from the sea by the tidal level during neap tides (Pearson \& Brawley 1996). At the temperatures/seasons at which all other sympatric fucoids (Fucaceae) reproduce in New England (e.g. Mathieson 1989, Bacon \& Vadas 1991, Speransky et al. 2000, Li \& Brawley 2004), zygotes would have attached to the rockpool substratum within 6 to 18 h post-fertilization (Kropf 1992), which would substantially limit dispersal. F. distichus is most closely related to the sympatric low shore species F. evanescens (e.g. Powell 1963, Serrão et al. 1999b) but only F. distichus is reproductive in winter. Although hypotheses about the evolution of traits cannot be tested, we can investigate the mechanisms that maintain the contrasting patterns of reproductive seasonality and dispersal capabilities seen in these congeneric species.

\section{CONCLUSION}

The combination of genetic, demographic and phenological data collected in this study enabled us to characterize the population dynamics of this marine alga. Population differentiation was influenced by a 
combination of the unique characteristics of each pool (position on the shore, local topography), as well as the spatial arrangement of pools within each site (number and distances among pools). Genetic diversity within pools was often low, and we propose that this is due to selfing. Despite high genetic structure, dispersal among pools appears to be common, and occurs predominately among neighboring pools. Dispersal is potentially enhanced via a delay in attachment of zygotes in the cold seawater temperatures experienced in winter and spring when it reproduces in Maine. Relative to congeneric species, reproducing in winter may be an adaptation that evolved in Fucus distichus as a consequence of the isolated nature of the rockpool habitat, and the restriction of reproduction to periods of calm water motion (neap, low tides).

Acknowledgements. We would like to thank J. Muhlin (University of Maine) for help in the field, Dr. C. Engel (Station Biologique de Roscoff) and C. Lage (University of Maine) for discussion about analyses, Dr. G. Pearson (University of Algarve) for providing data used in the dispersal model, and the DNA Sequencing Facility at the University of Maine. We are grateful to the National Science Foundation for support of this work (OCE- 99043).

\section{LITERATURE CITED}

Bacon LC, Vadas RL (1991) A model for gamete release in Ascophyllum nodosum (Phaeophyta). J Phycol 27:166-173

Barnay A, Ellien C, Gentil F, Thiebaut E (2003) A model on variation in larval supply: are populations of the polychaete Owenia fusiformis in the English Channel open or closed? Helgol Mar Res 56:229-237

Belkhir K, Borsa P, Chikhi L, Raufaste N, Bonhomme F (2000) Genetix, A Windows ${ }^{\mathrm{TM}}$ Based Software for Population Genetic Analyses. Laboratoire Génome, Populations, Interactions CNRS UMR 5000, Université de Montpellier II, Montpellier (available at www.univ-montp2.fr/ genetix/ genetix.htm)

Berry O, Tocher MD, Sarre D (2004) Can assignment tests measure dispersal? Mol Ecol 13:551-561

Bohonak AJ (2002) IBD (Isolation By Distance): a program for analyses of isolation by distance. J Hered 93:153-154

Brawley SH (1991) The fast block against polyspermy in fucoid algae is an electrical block. Dev Biol 144:94-106

Brown JH (1971) Mammals on mountaintops: Non equilibrium insular biogeography. Am Nat 105:467-478

Burton RS, Feldman MW (1981) Population genetics of Tigriopus californicus. II. Differentiation among neighboring populations. Evolution 35:1192-1205

Chapman ARO, Johnson CR (1990) Disturbance and organization of macroalgal assemblages in the northwest Atlantic. Hydrobiologia 192:233-252

Cody ML, Overton J (1996) Short-term evolution of reduced dispersal in island plant populations. J Ecol 84:53-61

Coleman MA, Brawley SH (in press) Are life history attributes good predictors of genetic diversity and structure: a case study of the intertidal alga Fucus spiralis (Heterokontophyta: Phaeophyceae). J Phycol

Cornuet JM, Piry S, Luikart G, Estoup A, Solignac M (1999) New methods employing multilocus genotypes to select or exclude populations as origins of individuals. Genetics 153:1989-2000

Coyer JA, Veldsink JH, Jones K, Stam WS, Olsen JL (2002) Characterization of microsatellite loci in the marine seaweeds, Fucus serratus and F. evanescens (Heterokontophyta; Fucaceae). Mol Ecol Notes 2:35-37

Coyer JA, Peters AF, Stam WT, Olsen JL (2003) Post-ice age recolonization and differentiation of Fucus serratus L. (Phaeophyceae; Fucaceae) populations in Northern Europe. Mol Ecol 12:1817-1829

Engel CR, Brawley SH, Edwards KJ, Serrão E (2003) Isolation and cross-species amplification of microsatellite loci from fucoid seaweeds Fucus vesiculosus, F. serratus and Ascophyllum nodosum (Heterokontophyta, Fucaceae). Mol Ecol Notes 3:180-182

Engel CR, Destombe C, Valero M (2004) Mating system and gene flow in the red seaweed Gracilaria gracilis: effect of haploid-diploid life history and intertidal rocky shore landscape on fine-scale genetic structure. Heredity 92: 289-298

Felsenstein J (2002) PHYLIP: Phylogenetic Inference Package, Version 3.6. University of Washington, Seattle, WA

Frankham R (1998) Inbreeding and extinction: Island populations. Conserv Biol 12:665-675

Gabriel W, Lynch M, Burger R (1993) Muller's ratchet and mutational meltdowns. Evolution 47:1744-1757

Gilg MR, Hilbish TJ (2003) The geography of marine larval dispersal: coupling genetics with fine-scale physical oceanography. Ecology 84:2989-2998

Goudet J (1995) FSTAT (ver. 1.2): a computer program to calculate F-statistics. J Hered 86:485-486

Grosberg R, Cunningham CW (2001) Genetic structure in the sea. From populations to communities. In: Bertness MD, Gaines SD, Hay ME (eds) Marine community ecology. Sinauer Associates, Sunderland, MA, p 61-84

Hansen MM, Mensberg KD (1996) Founder effects and genetic population structure of brown trout (Salmo trutta) in a Danish river system. Can J Fish Aquat Sci 53: 2229-2237

Hanski IA, Gilpin ME (1997) Metapopulation biology. Academic Press, San Diego, CA

Hanski I, Breuker CJ, Schöps K, Setchfield R, Nieminen M (2002) Population history and life history influence the migration rate of female Glanville Fritillary butterflies. Oikos 98:87-97

Hill JK, Thomas CD, Lewis OT (1999) Flight morphology in fragmented populations of a rare British butterfly, Hesperia comma. Biol Conserv 87:277-283

Hurlbert SH (1984) Pseudoreplication and the design of ecological field experiments. Ecol Monogr 54:187-211

Johnson MS, Black R (1998) Increased genetic divergence and reduced genetic variation in populations of the snail Bembicium vittatum in isolated tidal ponds. Heredity 80 : 163-172

Kropf DL (1992) Establishment and expression of cellular polarity in fucoid zygotes. Microbiol Rev 56:316-339

Lande R (1993) Risks of population extinction from demographic and environmental stochasticity and random catastrophes. Am Nat 142:911-927

Levins R (1969) Some demographic and genetic consequences of environmental heterogeneity for biological control. Bull Ent Soc Am 15:237-240

Li R, Brawley SH (2004) Improved survival under heat stress in intertidal embryos (Fucus spp.) simultaneously exposed to hypersalinity and the effect of parental thermal history. Mar Biol 114:205-213

Lynch M, Blanchard J, Houle D, Kibota T, Schultz S, Vas- 
silieva L, Willis J (1999) Perspective: spontaneous deleterious mutation. Evolution: 53:645-663

MacArthur HR, Wilson EO (1967) The Theory of Island Biogeography. Princeton University Press, Princeton, NJ

Mader HJ (1984) Animal habitat isolation by roads and agricultural fields. Biol Conserv 29:81-96

Marshall DJ, Semmens D, Cook C (2004) Consequences of spawning at low tide: limited gamete dispersal for a rockpool anemone. Mar Ecol Prog Ser 266:135-142

Maruyama T, Kimura M (1980) Genetic variability and effective population size when local extinction and recolonization of subpopulations are frequent. Proc Natl Acad Sci USA 77:6710-6714

Mathieson AC (1989) Phenological patterns of Northern New England seaweeds. Bot Mar 32:419-438

Mayr E (1954) Change of genetic environment and evolution. In: Huxley J, Hardy AC, Ford EB (eds) Evolution as a process. Allen \& Unwin, London, p 157-180

McCauley DE (1991) Genetic consequences of local population extinction and recolonization. Trends Ecol Evol 6:5-8

Moran GF, Brown AHD (1980) Temporal heterogeneity of outcrossing rates in Alpine Ash (Eucalyptus delegatensis R.T. Bak.). Theor Appl Gen 57:101-105

Murawski DA, Hamrick JL (1991) The effects of the density of flowering individuals on the mating systems of 9 tropical tree species. Heredity 67:167-174

Neraas LP, Spruell P (2001) Fragmentation of riverine systems: the origins of bull trout (Salvelinus confluentus) collected at the base of Cabinet Gorge Dam, Montana. Mol Ecol 10:1153-1164

Newman D, Pilson D (1997) Increased probability of extinction due to decreased genetic effective population size: experimental populations of Clarkia pulchella. Evolution 51:354-362

Page RDM (1996) TREEVIEW: An application to display phylogenetic trees on personal computers. Comput Appl Biosci 12:357-358

Palumbi SR (1994) Genetic divergence, reproductive isolation, and marine speciation. Annu Rev Ecol Syst 25:547-572

Pearson GA, Brawley SH (1996) Reproductive ecology of Fucus distichus (Phaeophyceae): an intertidal alga with successful external fertilization. Mar Ecol Prog Ser 143: 211-223

Pearson GA, Serrão EA, Brawley SH (1998) Control of gamete release in fucoid algae: sensing hydrodynamic conditions via carbon acquisition. Ecology 79:1725-1739

Piry S, Alapetite A, Cornuet JM, Paetkau D, Baudouin L, Estoup A (2004) GeneClass2: a software for genetic assignment and first generation migrants detection. J Hered 95:536-539

Powell AH, Powell GNV (1987) Population dynamics of male euglossine bees in Amazonian forest fragments. Biotropica 19:176-179

Powell HT (1963) Speciation in the genus Fucus L., and related genera. Syst Assoc Pub 5:63-77

Provine W B (1989) Founder effects and genetic revolutions in microevolution and speciation: an historical perspective. In: Giddings LV, Kaneshiro KY, Anderson WW (eds) Genetics, speciation and the founder principle. Oxford University Press, Oxford, p 43-76

Pulliam HR (1988) Sources, sinks and population regulation. Am Nat 132:652-661

Editorial responsibility: Otto Kinne (Editor-in-Chief), Oldendorf/Luhe, Germany
Rannala B, Mountain JL (1997) Detecting immigration by using multilocus genotypes. Proc Natl Acad Sci USA 94: 9197-9201

Reynolds J, Weir BS, Cockerham CC (1983) Estimation of the coancestry coefficient: Basis for a short-term genetic distance. Genetics 105:767-779

Rousset F (1997) Genetic differentiation and estimates of gene flow from $F$-statistics under isolation by distance. Genetics 145:1219-1228

Saccheri I, Kuussaari M, Kankare M, Vilman P, Fortelius W, Hanski I (1998) Inbreeding and extinction in a butterfly metapopulation. Nature 392:491-494

Schneider S, Roessli D, Excoffier L (2000) Arlequin: A software for population genetics data analysis. Version 2.000. Geneva: Genetics and Biometry Laboratory, University of Geneva

Sears JR (2002) NEAS keys to the benthic marine algae of the northeastern coast of North America from Long Island Sound to the Straight of Belle Isle, 2nd edn. Northeast Algal Society, Dartmouth, MA

Serrão EA, Pearson G, Kautsky L, Brawley SH (1996) Successful external fertilization in turbulent environments. Proc Natl Acad Sci USA 93:5286-5290

Serrão E, Brawley SH, Hedman J, Kautsky L, Samuelsson G (1999a) Reproductive success in Fucus vesiculosus (Phaeophyceae) in the Baltic Sea. J Phycol 35:254-269

Serrão EA, Alice LA, Brawley SH (1999b) Evolution of the Fucaceae (Phaeophyceae) inferred from nrDNA-ITS. J Phycol 35:382-394

Soule ME (1980) Thresholds for survival: maintaining fitness and evolutionary potential. In: Soule ME, Wilcox BA (eds) Conservation biology: an evolutionary-ecological perspective. Sinauer Associates, Sunderland, MA, p 151-169

Speransky S, Brawley SH, Halterman WA (2000) Gamete release is increased by calm conditions in the coenocytic green alga Bryopsis (Chlorophyta). J Phycol 36:730-739

Thomas CD, Hill JK, Lewis OT (1998) Evolutionary consequences of habitat fragmentation in a localized butterfly. J Anim Ecol 67:485-497

Van Oosterhout C, Hutchinson WF, Wills PDM, Shipley P (2004) MICRO-CHECKER: software for identifying and correcting genotyping errors in microsatellite data. Mol Ecol Notes 4:535-538

Wade MJ, McCauley DE (1988) Extinction and recolonization: their effects on the genetic differentiation of local populations. Evolution 42:995-1055

Wahlund S (1928) Zusammensetzung von Populationen und Korrelationserscheinungen vom Standpunkt der Vererbungslehre aus betrachet. Hereditas 11:65-105

Weir BS, Cockerham CC (1984) Estimating F-statistics for the analysis of population structure. Evolution 38:1358-1370

Whitlock MC (1992) Nonequilibrium population structure in forked fungus beetles: extinction, colonization, and the genetic variance among populations. Am Nat 139:952-970

Williams SL, Di Fiori RE (1996) Genetic diversity and structure in Pelvetia fastigiata (Phaeophyta: Fucales): does a small effective neighborhood size explain fine-scale genetic structure. Mar Biol 126:371-382

Won Y, Young CR, Lutz RA, Vrijenhoek RC (2003) Dispersal barriers and isolation among deep-sea mussel populations (Mytilidae: Bathymodiolus) from eastern Pacific hydrothermal vents. Mol Ecol 12:169-184

Wright S (1943) Isolation by distance. Genetics 28:114-138

Submitted: December 3, 2004; Accepted: April 26, 2005

Proofs received from author(s): August 26, 2005 